Research Paper:

\title{
Structural Model of Academic Procrastination Based on Personality Traits by Educational Motivation in Secondary High School Students
}

Suzan Ghanadi ${ }^{1}$ (D), Mohammad Kazem Fakhri ${ }^{*}$ (D), Yarali Doosti

1. Department of Psychology, Faculty of Humanities, Sari Branch, Islamic Azad University, Sari, Iran.

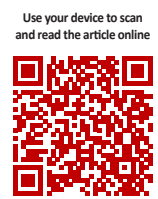

Citation: Ghanadi S, Fakhri MK, Doosti Y. Structural Model of Academic Procrastination Based on Personality Traits by Educational Motivation in Secondary High School Students. Avicenna J of Neuropsychophysiology. 2017; 4(2):57-64. http://dx.doi. org/10.32598/ajnpp.4.2.57

doi: : http://dx.doi.org/10.32598/ajnpp.4.2.57

Funding: See Page 62

(c) Copyright: The Author(s)

Article info:

Received: 18 August 2016

Accepted: 20 January 2017

Available Online: 01 May 2017

Keywords:

Structural equation models, Academic procrastination, Personality traits, Educational motivation

\begin{abstract}
Background: Procrastination is a prevalent behavior affecting all life aspects, especially educational fields. Educational procrastination is defined as unnecessary delay for doing assignments. Personality traits are very important in explaining procrastination. This study aimed to investigate the structural model of academic procrastination based on personality traits by student's educational motivation.
\end{abstract}

Materials and Methods: In the current cross-sectional descriptive-analytical study, the participants consisted of 400 students ( 171 boys and 231 girls) of secondary high school in Bojnord City, Iran in 2017-2018 academic year. The students were selected by the multistep random clustering sampling method from 3 girls' high schools and 3 boys' high schools (3 classes from each high school) from the north, south, east and west districts of the city. The relevant data were gathered by Academic Procrastination Scale, personality traits, and educational motivation questionnaires. Data analysis was done by structural equation modeling in LISREL V. 8.80.

Results: According to model fitting, direct effect of neuroticism conscientiousness and educational motivation upon academic procrastination was significant $(P<0.05)$. Also, the standard effects of neuroticism and conscientiousness upon educational procrastination (by educational motivation) were significant $(\mathrm{P}<0.05)$.

Conclusion: According to the results, anxiety management training for neurotic persons, as well as improving agreeableness rate will result in an increase in educational motivation and, in turn, a decrease in academic procrastination. 


\section{Introduction}

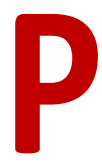

rocrastination for assignments occurs because of different reasons. This experience is known as a source of stress but seldom results in mental pain. However, in some people, procrastination may change to a behavioral model that disturbs life [1]. It is a prevalent event affecting all life aspects, especially educational fields [2]. Procrastination is an intentional delay in doing school assignments that may have negative results [3]. Academic procrastination is defined as unnecessary delay in doing homework [4]. Personality traits are very important in explaining procrastination. It is known as one personality feature with behavioral delay sign [5].

Normal personality field is defined by five factor personality trait. This model introduces main five dimensions for personality as neuroticism, extroversion, agreeableness, conscientiousness, and openness to experience [6, 7]. Evidently, there is a remarkable overlap between neuroticism and procrastination rate. Neuroticism is very similar to anxiety, adjective anxiety and negative affection [8]. Researchers believe that people are disgusted in doing stressful homework; Therefore, they show procrastination to delay their anxiety [9]. According to studies, there is a relationship between educational procrastination and conscientiousness. Based on literature review, there are relationships among procrastination and neuroticism, agreeableness and extroversion $[5,10,11]$.

However, academic procrastination does not accept effects by personality traits, motivation drive affecting persons' aims [12]. Motivation may result in lowering procrastination in students [10]. According to specialists' opinions, interest in other activities is the main reason for procrastination [13]. Steel introduced annoying homework as one of effective traits in procrastination [10]. Every person tries to avoid annoying stimulus. Personality traits are effective upon person's tendency to do assignments, however, an unpleasant task is more likely to be postponed [14].

Interest, enjoyment, being pleasant and tendency toward learning subjects may result in an enjoyable study [15]. Boring subjects may cause more procrastination. Therefore, students with procrastination experience unpleasant emotions [14]. Boosting motivation may result in decrease in procrastination signs [16-20]. Thus, this study aims to investigate the structural model of academic procrastination based on personality traits by student's educational motivation.

\section{Materials and Methods}

The present study was a correlational research with structural equation modeling. Study population consisted of all students in secondary high schools of Bojnord City, Iran in 2017-2018 academic year. Four hundred students (171 boys and 231 girls) were selected by the multistep random clustering sampling method among 3 girls' high schools and 3 boys' high schools ( 3 classes from each high school) from the north, south, east and west districts of the city. In order to determine the sample size, we used the sample size method introduced by Klein (2010).

Based on this method, 20 people is enough for every component of a questionnaire. Since, in this study, the studied questionnaires had 13 compartments, a sample of 260 people were required. Besides, in order to compensate for dropping samples, 400 female and male students at the secondary high school in the city of Bojnord were selected. The study inclusion criteria were studying in the secondary high schools in Bojnord during 2017-2018 academic year, having physical and mental ability to participate in the study, and giving their informed consent.

The exclusion criteria included reluctance to complete questionnaires or withdrawing from the study for any reason. The relevant data were collected by Academic Procrastination Scale designed by Solomon and Rothbelum (1984), Personality Trait Questionnaire designed by Costa and McCrae (1992) and Harter Educational Motivation Questionnaire (1981). Before the research, all participants were informed and gave their consent. Data analysis was done by structural equation modeling in LISREL V. 8.80.

\subsection{Study instruments}

\subsubsection{Academic Procrastination Scale}

Academic Procrastination Scale was designed by Solomon and Rothbelum (1984). It consists of 27 items with 3 components. The first component of "becoming ready for exams" included 8 questions like "I have dreams in studying for exams" and "I have difficulty in concentration". The second component of "becoming ready for assignments" included 11 items like "I postpone assignments to the other sessions" and the third component of "becoming ready for final term articles" included 8 items like "I postpone making ready article when I become obliged". In this scale, items $2,3,5,9,11,13,15$, $16,21,23,25$ were scored inversely and items 7, 8, 18, 19 were not used to estimate procrastination. 
It is necessary to state that the component of "becoming ready for final term articles" was deleted because it is not applicable to the students. The reliability of educational procrastination scale was estimated as 0.64 by the Cronbach's alpha test [21]. Solomon and Rothbelum estimated the validity of this scale by internal consistency validity as 0.84 . This scale reliability by Cronbach's alpha coefficients for all scales was estimated to be 0.91 in Iran and 0.88 by KMO test in factorial analysis method [22]. It is to be noted that in the current research, the reliability of academic procrastination questionnaire was 0.78 based on Cronbach's alpha test.

\subsubsection{Personality Trait Questionnaire}

Costa and McCrae (1992) used five factors of personality test consisting of neuroticism, extroversion, openness to experience, agreeableness and conscientiousness [23]. This scale has 60 questions, each factor is evaluated by 12 questions. Subject answers to each question based on Likert-type scale like "I disagree completely", "I disagree", "I have no opinion", "I agree" , and "I agree completely". Costa and McCrae (1992) estimated internal consistency (validity) of its subscales between 0.68 and 0.86 . They estimated their test validity as 0.50-0.75 [23]. Garousi et al. (2001) estimated its reliability coefficients as $0.86,0.73,0.56,0.68$ and 0.87 for neuroticism, extroversion, openness to experience, agreeableness and conscientiousness, respectively [24].

\subsubsection{Harter Scale of Educational Motivation}

Harter Scale of Educational Motivation consists of 33 items. This questionnaire is a revised form of Harter scale $(1980,1981)$ that measures educational motivation by two-dimensional questions (internal or ex- ternal). Each question is just related to one motivation (internal or external). It is scored based on Likert scale (never=1, seldom=2, sometime=3, most=4, near always $=5$ ). Harter estimated reliability coefficients of its subscales by Richardson 20 formula between 0.54 and 0.84 and retest coefficients between 0.48 and 0.63 [25]. Bohrani (2009) estimated validity and reliability of this scale in Iran [26].

\section{Results}

Table 1 presents descriptive statistics including mean and standard deviation, minimum and maximum score of research variables. According to Table 1 , the indicators related to skewness and kurtosis are within \pm 2 range. Therefore, the research variables have normal distribution. Also, the significance level of Levene test was more than 0.05 , so the variables have homogeneous variances in all states. In research conceptual model, conscientiousness and neuroticism variables were considered as exogenous variables, educational motivation variable as the mediator variable and educational procrastination variable as endogenous variable. This model analysis was done by the maximum likelihood method.

Model fitting indicators were estimated after analyzing research conceptual model by the maximum likelihood method. These indicators show research model coordination rate with experimental data. Table 2 shows the fitting indicators for elementary and reformed model of the present study. According to the results shown in Table 2, all fitting indicators for research suggested model exist in favorable range; these results show that $\chi^{2}$ indicator with freedom degree below 3, GFI, AGFI, NFI, TLI and CFI more than 0.9, RMSEA indicator below 0.1 and SRMR indicator below 0.8 . These

Table 1. Descriptive traits of research variables

\begin{tabular}{|c|c|c|c|c|c|}
\hline Variables & Mean (SD) & Maximum & Minimum & Skewness & Kurtosis \\
\hline Conscientiousness & $35.1(3.83)$ & 46 & 18 & -0.548 & -0.271 \\
\hline Neuroticism & $23.13(6.84)$ & 39 & 14 & 0.366 & -0.551 \\
\hline Educational motivation & $59.26(2.40)$ & 92 & 41 & -0.783 & -0.1 \\
\hline Academic procrastination & $58.52(6.13)$ & 80 & 25 & 0.731 & -0.258 \\
\hline
\end{tabular}

Table 2. Fitting indicators related to the research model

\begin{tabular}{ccccccccccc}
\hline Model & $\chi^{2}$ & df & $\chi^{2} / \mathbf{d f}$ & GFI & AGFI & NFI & TLI & CFI & RMSEA & SRMR \\
\hline $\begin{array}{l}\text { Suggestive } \\
\text { conceptual }\end{array}$ & 22.95 & 13 & 2.01 & 0.98 & 0.93 & 0.97 & 0.96 & 0.97 & 0.031 & 0.064 \\
\hline
\end{tabular}




\subsection{7}

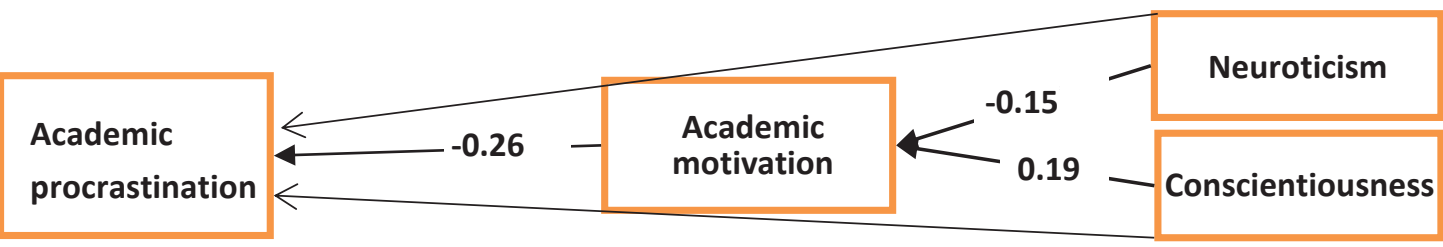

$-0.14$

AJNPP

Figure 1. Parameters in educational procrastination structural model based on personality traits with educational motivation mediator

results indicate that the present research conceptual model corresponds with the experimental data and these data support the research conceptual model.

Then, the estimated parameters of educational procrastination structural relations model based on personality traits by students' educational motivation were studied by the maximum likelihood evaluation method. Figure 1 shows the evaluated parameters for this model consisting of the standard path coefficients and their significance. According to Figure 1, the direct path coefficients toward motivation including neuroticism and conscientiousness and direct path coefficient of educational motivation toward educational procrastination are significant $(P<0.05)$. The maximum likelihood estimation method was used to survey the research direct hypothesis. Table 3 presents estimated parameters for these direct paths including nonstandard math coefficients, standard math coefficients, critical values and their significance.
The presented results in Figure 1 and Table 3 indicate that all path coefficients (direct effect) are significant $(P<0.05)$. Model fitting shows that neuroticism direct effect upon educational procrastination is positive and significant $(P=0.001)$. The direct effect of conscientiousness upon procrastination is negative and significant $(P=0.006)$. Finally, the direct effect of educational motivation upon educational procrastination is negative and significant $(P=0.001)$. Thus, the research structural model has suitable fitting. Finally, the Boot strap method was used to evaluate value and significance level of the indirect effects of the model. The results of this analysis are presented in Table 4.

According to Table 4, the standard effect of neuroticism upon educational procrastination (by educational motivation) is 0.02 significant $(P=0.017)$. Also, indirect effect of conscientiousness upon educational procrastination (by educational motivation) is -0.022 significant $(P=0.048)$.

Table 3. Parameters for research direct hypothesis estimated

\begin{tabular}{ccccc}
\hline Direct Path & Nonstandard Path Coefficient & $\boldsymbol{\beta}$ & Critical Values & P \\
\hline Neuroticism & 0.14 & 0.17 & -09 \\
Conscientiousness & -0.08 & -0.14 & -2.68 & 0.001 \\
Educational motivation & -0.61 & -0.26 & -4.84 & 0.001 \\
\hline
\end{tabular}

AJNPP

Table 4. Value and significance of indirect effects for measurement structural model

\begin{tabular}{cccc}
\hline Indirect Path & Standard Value & Upper & Lower \\
\hline $\begin{array}{c}\text { Neuroticism upon academic procrastination } \\
\text { (by educational motivation) }\end{array}$ & 0.026 & 0.009 & 0.047 \\
$\begin{array}{c}\text { Conscientiousness upon educational procrastination } \\
\text { (by educational motivation) }\end{array}$ & -0.022 & -0.041 & -0.004 \\
\hline
\end{tabular}




\section{Discussion}

This study aimed to investigate the structural model of academic procrastination based on personality traits by educational motivation among students. Based on the model fitting, direct effect of neuroticism conscientiousness and educational motivation upon academic procrastination was significant $(P<0.05)$. Also, the standard effects of neuroticism and conscientiousness upon educational procrastination (by educational motivation) were significant $(P<0.05)$. According to the results, the direct effect of neuroticism upon educational procrastination is positive and significant. People with higher negative emotion had weak adaptation rate and low impulse control. Anxiety is one of the effective factors in creating procrastination. It is very clear among neurotic persons $[10,21]$.

In fact, a neurotic person chooses procrastination to delay his/her anxiety. Lazarus and Folkman (1984) theory on stress and coping styles situation evaluating item is more important than anxiety and avoidance [27]. According to this theory, a person evaluates his/her ability and difficulty of his/her work. Then, he/ she experiences anxiety against unpleasant situations and finally chooses coping styles like avoidance [28]. In fact, the person prefers low reinforcements to high reinforcements. This theory may clearly explain negative emotions and procrastination.

The results of the second hypothesis indicate that conscientiousness has direct and negative effect upon educational procrastination. Conscientiousness shows responsibility rate and achievement need. Responsible people succeed in different aspects of their lives. Agreeableness describes impulses control ability well and is facilitator task-based and aim-based behavior [29]. Individual differences are a base of responsibility that may assist in self-control, active planning, organizing, and doing tasks. Conscientious person is goal-oriented and decisive [30].

Procrastination is the indicator of lack of agreeableness and self-regulation [14]. It is related to disturbance, low organization, low achievement motivation and difference between goal and action. Planning and organizing are signs of self-regulation that may result in a decrease in procrastination. Achievement motivation is the other aspect of conscientiousness that has strong relationship with procrastination. People with a high level of achievement motivation have some goals and changes in performance. Achievement motivation may result in decreasing aversion toward work [31].
According to the third hypothesis, the direct effect of educational motivation upon procrastination is negative and significant [10]. Internal motivation refers to learning solely but external motivation relates to the other factors. In other words, internal motivation includes valuation by students to learn interesting subjects and domination of feeling upon learning matters and external learning refers to encouraging by teachers, taking marks and other rewards. Researchers show that students with internal motivation have better educational performance than other students [19].

Rakes (2010) believed that lack of internal motivation and no self-regulation might result in an increase in educational procrastination. Interestingly, enjoyment, pleasant tasks and tendency toward learning subjects may result in sound and enjoyable study [19]. The results indicate that the indirect standard effect of neuroticism upon educational procrastination (by educational motivation) is significant. Steel (2007) stated that neuroticism is similar to anxiety traits. Anxious people show more procrastination [10].

Solomon and Rothbelum (1984) stated that fear of exam failure increases anxiety and person chooses procrastination to delay his/her anxiety [21]. Since neuroticism is a personality trait, it may affect educational motivation. Therefore, these people have low educational motivation that may result in an increase in academic procrastination. The results indicate that conscientiousness effect upon educational procrastination (by educational motivation) is negatively significant. People with high conscientiousness are agreeable, are aware of themselves, and have better motivation. Therefore, there is a positive and significant relationship between conscientiousness and educational motivation. Procreative students are weak in planning their goals and postpone their homework to other time. In fact, learners with internal motivation have little procrastination [32]. It seems that self-regulation and self-efficacy may result in the best challenge. These internal values originate from psychological needs, curiosity and innate attempts to grow that may result in their adjustment $[1,33]$.

Many students have degrees of depression that can increase their self-efficacy and internal motivation to enjoy their homework. Internal motivation may result in better behavior because of creating interest [34]. The current study had some limitations that should be considered. First, the data collecting tools were self-report questionnaires, thus some questions may not be answered truly. Second, the data were collected from a sample of secondary high school students in the Bo- 
jnord City and cannot be generalized to other students in Iran. Therefore, it is suggested to conduct a research on the other groups of students, and then compare its results with our results.

\section{Conclusion}

The results of this study show that anxiety management training for neurotic persons and also increasing agreeableness rate may result in increase in educational motivation and then decrease in educational procrastination.

\section{Ethical Considerations}

\section{Compliance with ethical guidelines}

All ethical principles were considered in this article. The participants were informed about the purpose of the research and its implementation stages and signed the informed consent; They were also assured about the confidentiality of their information; Moreover, They were allowed to leave the study whenever they wish, and if desired, the results of the research would be available to them.

\section{Funding}

This research did not receive any specific grant from funding agencies in the public, commercial, or not-forprofit sectors.

\section{Conflict of interest}

The authors have no conflict of interest to declare.

\section{References}

[1] Rozental A, Carlbring P. Understanding and treating procrastination: A review of a common self-regulatory failure. Psychology. 2014; 5(13):1488-502. [DOI:10.4236/ psych.2014.513160]

[2] Eckert M, Ebert DD, Lehr D, Sieland B, Berking M. Overcome procrastination: Enhancing emotion regulation skills reduce procrastination. Learning and Individual Differences. 2016; 52:10-8. [DOI:10.1016/j.lindif.2016.10.001]

[3] Klingsieck KB. Procrastination: When good things don't come to those who wait. European Psychologist. 2013; 18(1):24-34. [DOI:10.1027/1016-9040/a000138]

[4] Yong FL. A study on the assertiveness and academic procrastination of English and communication students at a pri- vate university. American Journal of Scientific Research. 2010; 9:62-71.

[5] Karatas H. Correlation among academic procrastination, personality traits, and academic achievement. Anthropologist. 2015; 20(1):243-55.

[6] Dwan T, Ownsworth T, Donovan C, Lo AHY. Reliability of the NEO five factor inventory short form for assessing personality after stroke. International Psychogeriatrics. 2017 29(7):1157-68. [DOI:10.1017/S1041610217000382] [PMID]

[7] McCrae RR, Costa Jr PT. Brief versions of the NEOPI-3. Journal of Individual Differences. 2007; 28(3):116-28. [DOI:10.1027/1614-0001.28.3.116]

[8] Onwuegbuzie AJ. Academic procrastination and statistics anxiety. Assessment \& Evaluation in Higher Education. 2004; 29(1):3-19. [DOI:10.1080/0260293042000160384]

[9] Hashemi T, Mostafavi F, Mashinchi Abbasi N, Badri R. [Role of goal orientation, self-efficacy of self-regulation and personality in procrastination (Persian)]. Contemporary Psychology. 2012; 7(1):73-84.

[10] Stajkovic AD, Bandura A, Locke EA, Lee D, Sergent K. Test of three conceptual models of influence of the big five personality traits and self-efficacy on academic performance: A meta-analytic path-analysis. Personality and Individual Differences. 2018; 120:238-45. [DOI:10.1016/j.paid.2017.08.014]

[11] Schouwenburg HC, Groenewoud J. Study motivation under social temptation; effects of trait procrastination. Personality and Individual Differences. 2001; 30(2):229-40. [DOI:10.1016/S0191-8869(00)00034-9]

[12] Grund A, Fries S. Understanding procrastination: A motivational approach. Personality and Individual Differences. 2018; 121:120-30. [DOI:10.1016/j.paid.2017.09.035]

[13] Howell AJ, Watson DC. Procrastination: Associations with achievement goal orientation and learning strategies. Personality and Individual Differences. 2007; 43(1):167-78. [DOI:10.1016/j.paid.2006.11.017]

[14] Kitsantas A, Steen S, Huie F. The role of self-regulated strategies and goal orientation in predicting achievement of elementary school children. International Electronic Journal of Elementary Education. 2017; 2(1):65-81.

[15] Cao L. Differences in procrastination and motivation between undergraduate and graduate students. Journal of the Scholarship of Teaching and Learning. 2012; 12(2):39-64.

[16] Koushki S, Liaght R, Kamali A. Relationship between attributional styles, self-regulation and educational procrastination in student. International Journal of Psychological Research. 2014; 3(3):184-91.

[17] Afshari M, Yazdi Ravandi S, Zamani A, Fadaei F, Rezaei T, Taslimi Z. [Evaluation of workshops Student Research Center of Hamadan University of Medical Science from the perspective of participating students in 2015 (Persian)]. Pajouhan Scientific Journal. 2016; 14(3):1-10. [DOI:10.21859/psj-140301]

[18] Rakes GC, Dunn KE, Rakes TA. Attribution as a predictor of procrastination in online graduate students. Journal of Interactive Online Learning. 2013; 12(3):103-21.

[19] Klassen RM, Krawchuk LL, Rajani S. Academic procrastination of undergraduates: Low self-efficacy to self-regulate 
predicts higher levels of procrastination. Contemporary Educational Psychology. 2008; 33(4):915-31. [DOI:10.1016/j. cedpsych.2007.07.001]

[20] Solomon LJ, Rothblum ED. Academic procrastination: Frequency and cognitive-behavioral correlates. Journal of Counseling Psychology. 1984; 31(4):503-9. [DOI:10.1037/0022-0167.31.4.503]

[21] Jokar B, Delavarpour M. [The relationship between Academic procrastination and goal achievement (Persian). Journal of New thoughts on Education. 2007; 3(3):61-80. [DOI:10.22051/JONTOE.2007.312]

[22] Costa Jr PT, McCrae RR. Domains and facets: Hierarchical personality assessment using the revised NEO personality inventory. Journal of Personality Assessment. 1995; 64(1):21-50. [DOI:10.1207/s15327752jpa6401_2] [PMID]

[23] Garousi Farshi MT, Mehryar AH, Ghazi Tabatabaei M [Application of the NEOP I-R test analytic evaluation of it's characteristisc and factorial structure among university students (Persian)]. Journal of Humanities. 2001; 11(39):173-98.

[24] Harter S. A new self-report scale of intrinsic versus extrinsic orientation in the classroom: Motivational and informational components. Developmental Psychology. 1981; 17(3):300-12. [DOI:10.1037/0012-1649.17.3.300]

[25] Bohrani M. The study of validity and reliability of Harter's scale of educational motivation. Psychological Studies. 2009; 5(1):51-72.

[26] Lazarus RS. Stress, appraisal, and coping. Berlin: Springer; 1984.

[27] Folkman S. Stress: Appraisal and coping. In: Gellman M, Turner JR, editors. Encyclopedia of Behavioral Medicine. Berlin: Springer; 2012. [DOI:10.1007/978-1-4419-1005-9_215]

[28] Allik J, Church AT, Ortiz FA, Rossier J, Hřebíčková M, de Fruyt F, et al. Mean profiles of the NEO personality inventory.Journal of Cross-Cultural Psychology. 2017; 48(3):402-20. [DOI:10.1177/0022022117692100]

[29] Costa PT, McCrae RR. The revised neo personality inventory (neo-pi-r). The SAGE handbook of personality theory and assessment. 2008; 2(2):179-98.

[30] Balkis M, Duru E. Procrastination, self-regulation failure, academic life satisfaction, and affective well-being: Underregulation or misregulation form. European Journal of Psychology of Education. 2016; 31(3):439-59. [DOI:10.1007/s10212-015-0266-5]

[31] Katz I, Eilot K, Nevo N. “I'll do it later": Type of motivation, self-efficacy and homework procrastination. Motivation and Emotion. 2014; 38(1):111-9. [DOI:10.1007/s11031-013-9366-1]

[32] Yazdi-Ravandi S, Taslimi Z, Ahmadpanah M, Ghaleiha A Adjustment to diabetes among diabetic patients: The roles of social support and self-efficacy. Avicenna Journal of Neuropsychophysiology. 2016; 3(1):1-5. [DOI:10.17795/ajnpp-37470]

[33] Rezaei T, YazdiRavandi S, Ghaleiha A, Seif Rabiei MA. [Depression among medical students of Hamadan University of Medical Sciences in 2014: The role of demographic variables (Persian)]. Pajouhan Scientific Journal. 2015; 13(4):1-8.

[34] Hossein Chari M, Dehghani Y. [Predict the degree of academic procrastination based on self-regulation strategies in learning (Persian)]. Quarterly Journal of Research in Educational Systems. 2008; 2(4):63-73. 
